\title{
ASPECTOS LEGAIS E DESTINAÇÃO DURANTE O RESGATE de animais silvestres nativos no Brasil
}

\section{Legal aspects and destination during the rescue of native wild animals in Brazil}

\author{
Brenda Mendes França ${ }^{1}$, Carolina Soares Santos ${ }^{1}$, Giulia Moreno Matrone ${ }^{1}{ }^{\circledR}$, Lívia Alesse Bertoni ${ }^{1}$, \\ Pietra Guerra Gonçalves ${ }^{1}$, Tabatha da Costa Oliveira ${ }^{1}$, Liege Cristina Garcia da Silva ${ }^{2}$ \\ *Autor Correspondente: Giulia Moreno Matrone. Rua Passos, 249, \\ apto. 33 A, Belenzinho, São Paulo, SP, Brasil. CEP 03058-010. \\ E-mail: giulia.moreno.m@gmail.com
}

\begin{abstract}
Como citar: FRANÇA, B. M. et al. Aspectos legais e destinação durante o resgate de animais silvestres nativos no Brasil. Revista de Educação Continuada em Medicina Veterinária e Zootecnia do CRMV-SP, São Paulo, V. 19, n. 1, 2021, e38134, DOl: https://doi.org/10.36440/recmvz.v19i1.38134.
\end{abstract}

Cite as: FRANÇA, B. M. et al. Legal aspects and destination during the rescue of native wild animals in Brazil. Journal of Continuing Education in Veterinary Medicine and Animal Science of CRMV-SP, São Paulo, V. 19, n. 1, 2021, e38134, DOl: https://doi.org/10.36440/recmvz.v19i1.38134.

\section{Resumo}

0 resgate de animais silvestres está diretamente relacionado à preservação da fauna silvestre do País. Os animais resgatados pela Polícia Militar Ambiental são encaminhados aos Centros de Triagem e Reabilitação de Animais Silvestres (Cetras), conforme estabelecido pela Resolução Conama no 489/ 2018, para identificação, avaliação e, em algumas vezes, serem reabilitados antes de ser determinado o seu destino. Tratando-se de animais acidentados, há duas principais origens: animais atropelados, principalmente em rodovias, e animais provenientes de acidentes em centros urbanos. 0 tráfico de animais silvestres também causa um impacto importante na fauna brasileira, principalmente em espécies vulneráveis e/ou em extinção. É de extrema importância a ação dos centros de conservação de espécies, com vistas à redução dos altos índices de animais incluídos na lista de espécies ameaçadas de extinção.

Palavras-chave: Resgate. Animais Silvestres. Brasil. Legislação Ambiental.

\section{Abstract}

Rescuing wild animals is directly related to the preservation of the country's wildlife. The animals rescued by the Environmental Military Police are sent to the Wild Animal Screening and Rehabilitation Centers (Cetras), as established by Conama Resolution n. 489/2018, for identification, evaluation and sometimes being rehabilitated before determining their destination. In the case of injured animals, there are two main origins: animals run over, mainly on highways, and animals from accidents in the urban centers. Trafficking of wild animals also causes an important impact on the Brazilian fauna,

1 Discente, Universidade Anhembi Morumbi, Faculdade de Medicina Veterinária, São Paulo, SP, Brasil

2 Docente, Universidade Anhembi Morumbi, Faculdade de Medicina Veterinária, São Paulo, SP, Brasil 
especially on rare and/or endangered species. The action of species conservation centers is extremely important in order to reduce the high levels of animals on the endangered threat list.

Keywords: Rescue. Wild Animals. Brazil. Environmental Legislation.

\section{Introdução}

0 resgate de animais silvestres, por descrição, consiste na ação especializada de captura ou recolhimento por autoridades competentes de animais encontrados fora de seu habitat natural, colocando em perigo a sua vida e/ou das pessoas (AMARAL et al., 2015). Estes animais provêm do tráfico, de acidentes (principalmente, atropelamentos) ou do aparecimento em centros urbanos. Os animais resgatados pelo Policiamento Militar Ambiental são encaminhados para os Centros de Triagem e Reabilitação de Animais Silvestres (Cetras), conforme Resolução Conama no 489/ 2018, para serem identificados, avaliados e algumas vezes reabilitados, antes de ser determinado os seus destinos.

Resgatar animais silvestres está diretamente relacionado à preservação da fauna silvestre do país. O Livro Vermelho, do ano de 2018, do ICMBio (Instituto Chico Mendes de Conservação da Biodiversidade) destaca o reconhecimento oficial no Brasil de 1.173 espécies ameaçadas de extinção. Com esta atualização, 170 espécies saíram da lista e alguns fatores contribuíram para isso, como 0 reencontro de espécies extintas, maior conhecimento sobre as espécies, aumento populacional e aumento de proteção do seu habitat.

A expansão urbana, ampliação da malha rodoviária, agronegócio, degradação de ambientes naturais e incêndios florestais são exemplos das principais causas de diminuição do número de animais silvestres. A ação antropogênica impactou os habitats desses animais, visto que, o crescimento dos centros urbanos se deu de forma rápida e desorganizada. Dessa forma, as áreas com habitats naturais para a fauna silvestre, que ocupavam uma grande e contínua extensão, foram reduzidas. Tal processo, é chamado de fragmentação do habitat (SHAFER, 1990; DI GIULIO et al., 2009).

As rodovias representam um dos maiores males da civilização quanto aos impactos sobre o ambiente natural e causam problemas também ao próprio meio antrópico (BANDEIRA; FLORIANO, 2004). A construção de rodovias pode determinar inúmeros impactos sobre o meio ambiente, como desmatamento, perda de diversidade biológica, alteração do sistema natural de drenagem e degradação do solo (PANAZZOLO et al., 2012), além de ocasionarem atropelamentos da fauna silvestre. A base de dados da Polícia Militar Rodoviária do Estado de São Paulo (PMRSP) refere que, entre os anos de 2003 e 2013, cerca de 28.724 animais (domésticos e silvestres) foram atropelados no estado, resultando em uma média de 2.611 animais atropelados/ano e um custo para a sociedade, estimado em R\$ 56.550.000,00 por ano. Sendo, este custo, proveniente de gastos com pessoas e veículos envolvidos, serviço público e danos à propriedade pública (ABRA et al., 2019).

O tráfico de animais silvestres também causa um impacto importante na fauna brasileira, principalmente para as espécies raras e/ou em extinção. No Brasil, as atividades de caça e tráfico retiram de seus habitats cerca de 12 mil animais por ano. De fato, devido às condições precárias e insalubres de transporte, cerca de $90 \%$ desses animais morrem antes mesmo de chegarem ao destino final (VIDOLIN et al., 2004).

Diversas medidas têm sido implantadas para combater o risco de extinção das espécies ameaçadas, como Planos de Ação Nacional das Espécies Ameaçadas de Extinção ou do Patrimônio Espeleológico (PAN) e Unidades de Conservação (UC), mais especificamente, os Refúgios de Vida Silvestre (RVS) que, de acordo com o Art. $13^{\circ}$ da Lei 9.985, de 18 de julho de 2000, "têm como objetivo proteger ambientes naturais onde se asseguram condições para a existência ou reprodução de espécies ou comunidades da flora local e da fauna residente ou migratória" (BRASIL, 2000). Além destes, existem as bases de dados e sistemas de informação, sistemas de monitoramento (como o Sistema Urubu e 
Banco de Atropelamento de Fauna Selvagem) e Centros de Triagem e Reabilitação de Animais Silvestres (Cetras) que têm suas atividades definidas pela Resolução Conama no 489/ 2018.

\section{Objetivos}

O presente trabalho foi delineado para compilar dados e informações sobre os aspectos legais e a destinação durante o resgate de animais silvestres nativos no Brasil.

\section{Síntese dos dados}

De acordo com a Lei no 5.197/1967 de Proteção à Fauna, em seu artigo 10: "Os animais de quaisquer espécies, em qualquer fase do seu desenvolvimento e que vivem naturalmente fora do cativeiro, constituindo a fauna silvestre, bem como seus ninhos, abrigos e criadouros naturais são propriedades do Estado, sendo proibida a sua utilização, perseguição, destruição, caça ou apanha" (BRASIL, 1967). Assim, a partir desta lei, coube ao Estado a responsabilidade de proteger, cuidar, preservar e conservar a fauna silvestre. A citada lei também permitiu a implantação de projetos de conservação ex situ com ação da iniciativa privada.

Atualmente, as principais causas de extinção dos animais silvestres nativos do Brasil são o tráfico, a degradação e a fragmentação de ambientes naturais, resultante da abertura de grandes áreas para implantação de pastagens ou agricultura convencional, extrativismo desordenado, expansão urbana, ampliação da malha viária, poluição, incêndios florestais, formação de lagos para hidrelétricas e mineração de superfície. Esses fatores reduzem o total de habitats disponíveis às espécies e aumentam o grau de isolamento entre suas populações, diminuindo o fluxo gênico entre elas, o que pode acarretar perdas de variabilidade genética e, eventualmente, a extinção de espécies (AMARAL et al., 2015).

Para combater essas ameaças, o Programa Pró-espécies organiza e estabelece as ações de prevenção, conservação, manejo e gestão. A partir disso, se nota a importância do trabalho de resgate de fauna, que Clark Jr. apud Drews (1999) refere que deve abranger três pilares: o bom cuidado e reabilitação dos animais, a educação do público e a participação na política e em atividades de manejo que incorporem conhecimentos adquiridos a partir dos animais cativos para o benefício da fauna geral. 0 mesmo autor ainda cita que, após translocações e reintroduções, deve haver um acompanhamento dos animais libertados.

\section{Origem}

Existem três tipos de vitimização de animais: acidentados (decorrente de atropelamentos ou acidentes urbanos), resgatados e apreendidos, oriundos do tráfico, (BRANCO, 2015). Em alguns casos também ocorre a entrega voluntária, de acordo com a Lei de Crimes Ambientais, Lei no 9.605/1998, que normatiza a entrega de animais silvestres de forma voluntária de particulares que mantinham os animais em condições de cativeiro ilegal.

Como mencionado, o tráfico é um dos principais motivos da extinção de animais silvestres tanto no Brasil como no mundo e ainda é uma atividade muito presente no País, apesar da formulação da Lei no 9.605/1998, que proíbe o comércio ilegal de animais silvestres (BRASIL, 1998). Acredita-se que esse comércio proibido por lei se dá pela alta biodiversidade brasileira, que representa $15 \%$ a $20 \%$ da biodiversidade mundial (LACAVA, 2000), pela cobiça e procura do mercado internacional e pela alta lucratividade, visto que, este mercado movimenta cerca de um bilhão de reais no país por ano e 20 bilhões de dólares no mundo (RENCTAS, 2002). A maioria dos animais traficados é proveniente das regiões Norte, Nordeste e Centro-Oeste do País (GONÇALVES, 2009; ARAUJO et al., 2010). 
O uso da internet também favoreceu muito o crescimento do tráfico de animais silvestres, pois tornou possível o acesso a um maior público, nacional e internacional. A utilização de fóruns de conversas, websites de leilões e grupos fechados em redes sociais, como o Facebook, facilita as vendas, já que, suas regras são manipuláveis e tais empresas possuem políticas de privacidade que dificultam as investigações (IFAW, 2007; KRISHNASAMY; STONE, 2016; YU; JAI, 2015; HERNANDEZ; CARVALHO, 2006; ACOSTA apud BRASIL, 2004). Com a adição deste novo meio de comércio ilegal, a minimização do tráfico fica ainda mais prejudicada, visto que, as leis de regulamentação não preveem punições graves, e os órgãos de fiscalização não funcionam adequadamente (BASTOS et al., 2008). Apesar do crescimento alarmante do tráfico, existem tentativas de reverter essa situação, por meio de ações fiscalizatórias que partem de denúncias anônimas ou monitoramento da própria Polícia Militar Ambiental.

Os animais acidentados apresentam duas origens principais: animais atropelados, principalmente em rodovias, e animais provenientes de acidentes em centros urbanos. Devido à expansão das cidades, os habitats naturais dos animais silvestres se tornaram cada vez mais limitados, implicando em seu aparecimento no meio urbano para buscar abrigo ou alimento (BRANCO, 2015). Muitas vezes, o aparecimento vem acompanhado de acidentes: choques elétricos em fiações, afogamentos em piscinas, mordeduras de animais domésticos e, em alguns casos, agressões causadas pelos seres humanos. Na realidade o que se constata é uma grande desinformação da população sobre esses animais e sobre quais medidas devem ser tomadas quando do encontro de animais silvestres feridos, que necessitem de resgate.

De fato, a construção de rodovias ocasiona um fenômeno chamado de fragmentação de habitat, que limita a colonização e a alimentação dos animais (PRIMACK; RODRIGUES, 2001), motivo pelo qual muitos animais cruzam as pistas das rodovias e acabam sendo atropelados. Um agravante dessa situação é a presença de alimentos e outros resíduos orgânicos deixados, e, muitas vezes, jogados nas pistas, que acabam sendo atrativos para os animais (LIMA; OBARA, 2013). Existe um ciclo de atropelamentos, pois muitas vezes não há empresas responsáveis pelo recolhimento das carcaças dos animais, que se tornam atrativas para animais carniceiros levando a novos atropelamentos (GONÇALVES, 2018). Cirino e Freitas (2018) ressaltaram que, o gênero com maior número de ocorrências é o Didelphis (gambás), com 950 atropelamentos registrados em doze estados brasileiros no período de 2004 a 2015, distribuídos em três espécies diferentes. Em contrapartida, Huijser, Abra e Duffield (2013) e Abra (2019) citam que os animais com maiores relatos de atropelamentos são mamíferos de porte médio, entre os quais, a capivara (Hydrochoerus hydrochaeris) é a mais citada, tanto por conta do seu tamanho e peso, pois podem levar os veículos a danos, quanto por ser uma ameaça à integridade física humana.

Com o intuito de controlar ou até mesmo minimizar os impactos ambientais ocasionados pelas rodovias, são realizados monitoramentos durante a sua construção, desde o período de obra até o período de operação. O CBEE (Centro Brasileiro de Estudos em Ecologia de Estradas) propôs a implantação do Sistema Urubu (CBEE, 2014), uma rede social criada em 2014, que visa a conservação da biodiversidade brasileira por meio da reunião, sistematização e disponibilização de informações sobre a mortalidade da fauna, para auxiliar o governo e as concessionárias das rodovias, na tomada de decisões que promovam a redução de tais impactos. Atualmente, o Sistema conta com um aplicativo para os usuários fotografarem animais atropelados encontrados em estradas, tanto silvestres quanto domésticos e, dessa forma são identificadas a espécie e as áreas prioritárias para conservação. 0 aplicativo encontra-se disponível para download gratuito na loja de compras de celulares com os sistemas iOS e Android. 


\section{Transporte e contenção}

Os órgãos relacionados à fase de transporte dos animais necessitados de resgate devem possuir licenciamento ambiental estadual, CPRH (Agência Estadual de Meio Ambiente). A Lei Complementar no 140/2011, que fixa a cooperação da União, Estado e Municípios na gestão de fauna silvestre cita que a Polícia Militar Ambiental e Rodoviária, a Guarda Municipal Ambiental e o Corpo de Bombeiros são os órgãos que realizam esse transporte.

0 transporte de animais resgatados é dividido em: interno (quando o animal é transportado dentro do próprio alojamento, isto é, dentro do centro de resgate) e externo (quando o animal necessita ser transportado para outro local, por exemplo do local de onde foi resgatado para o centro de triagem) (AMARAL et al., 2015). 0 momento do transporte é o mais estressante para o animal e deve ser realizado de acordo com as técnicas apropriadas, que não caracterizem maus-tratos. Para um animal silvestre ser transportado ele deve ser adequadamente contido. Para os animais de fácil contenção devem ser empregados: ganchos, luvas de couro, puçás, cambões, pinções, redes e caixas de contenção (AMARAL et al., 2015).

Em algumas situações, o transporte dos animais resgatados só pode ser realizado com o emprego de contenção química realizada por médicos-veterinários. Neste procedimento podem ser empregados fármacos destinados a promover sedação, analgesia, relaxamento muscular ou alterações do comportamento do animal. Sabe-se que não existem medicamentos de contenção química que causem todos estes efeitos simultaneamente no grau ideal para todas as espécies, então, é comum a utilização da associação de mais de um fármaco para que o procedimento seja realizado (BERTOZZO et al., 2008). Os fármacos mais comumente utilizados são: Cetamina (MASSONE, 2003); (KILPATRICK et al., 1999), Xilazina (CUBAS, 2002; SPINOSA; GORNIAK; BERNARDI, 1999), associação de ambos (ANDRADE, 2002), associação Tiletamina-Zolazepam (SPINOSA; GORNIAK; BERNARDI, 1999), agentes inalatórios (CUBAS, 2002), entre outros. É importante ressaltar a necessidade da manutenção de uma distância adequada do animal a ser contido, pois ele pode reagir em decorrência de estresse ou mesmo se evadir. Alguns dos equipamentos utilizados para respeitar essa distância são: zarabatana, pistola e espingarda anestésica.

\section{Órgãos de resgate}

Os animais resgatados são encaminhados para diferentes locais regulamentados e autorizados pelo SIMA (Secretaria de Infraestrutura e Meio Ambiente) do Estado de São Paulo (segundo Decreto no 64.132, de 11 de março de 2019) como: Cetras (Centro de Triagem e Reabilitação de Animais Silvestres) e jardins zoológicos, como o Zoológico de Guarulhos (SP), o Zoológico Municipal "Quinzinho de Barros', em Sorocaba (SP), e a Fundação Parque Zoológico de São Paulo (FPZSP), que possuem a finalidade de receber, identificar, marcar, triar, avaliar, recuperar, reabilitar e destinar os animais da fauna silvestre.

Após a chegada dos animais aos centros apropriados para a recepção, eles são submetidos a um processo de conferência da identificação taxonômica, marcação individual (com a aplicação de anilhas ou microchips), além de avaliação física e comportamental. Com base nos resultados dessa avaliação prévia, são submetidos à quarentena, que é um período de isolamento do animal para a observação mais detalhada, para que se evite a contaminação do local e possam ser detectadas doenças preexistentes. Este processo de permanência nos Centros destina-se a promover a recuperação, reabilitação e tratamento dos animais, para, posteriormente, ser definida sua destinação. 
O Cetras classifica as destinações como: soltura direta (devolução após triagem), soltura monitorada (soltura após curto período de cativeiro) e atendimento a projetos de conservação da espécie (encaminhamento para instituições de pesquisa e zoológicos). A Instrução Normativa (Ibama) $n^{\circ} 23$, de 31 de dezembro de 2014, salienta que a soltura imediata deve ser priorizada, desde que haja indícios de que o animal foi recém-capturado, ou que não apresenta problemas que possam impedir a sua sobrevivência, ou que seja de ocorrência natural no local.

Quando não é possível a soltura imediata, os animais são encaminhados, com autorização dos órgãos ambientais e governos estaduais (conforme a Lei Complementar no 140/2011, que dá autonomia de decisão para os mesmos), a cativeiros, zoológicos, criadouros ou Asas (Áreas de Soltura de Animais Silvestres), que são propriedades rurais cadastradas. A Instrução Normativa ICMBio nº 23 de 2014 - Art. 18, refere que as Unidades de Conservação (UC) também podem ser usadas para a soltura imediata destinada a reintrodução de espécies, desde que os critérios da Lei nº 9985/2000 sejam respeitados. A soltura pode ser realizada apenas em UC's, sob gestão federal, após autorização de seus gestores e da Secretaria de Infraestrutura e Meio Ambiente (SIMA), quando no estado de São Paulo.

\section{Conclusão}

A ação dos centros de conservação de espécies é de extrema importância para diminuir os altos índices dos animais ameaçados de extinção. É certo que o Cetras é o principal órgão responsável para enfrentar essa problemática, porém ele pode receber ajuda da população para otimizar a sua eficácia.

A conscientização ambiental da população é necessária, pois toda a ação do homem reflete diretamente no bioma brasileiro. Sendo assim, é válido ressaltar que a preservação da fauna parte diretamente da consciência social.

Portanto, deve-se investir em projetos que englobem todos os níveis sociais, para orientação dos procedimentos a serem realizados quando do encontro de um animal silvestre em perigo ou na hipótese de sua eventual aparição em centros urbanos. Os cidadãos devem ser instruídos para telefonarem para um órgão responsável e observarem a condição dos animais. Isto poderá ser obtido com a realização de investimentos em folhetos informativos distribuídos em pedágios e abordagem do tema durante 0 processo de obtenção da carteira nacional de habilitação. Caso os indivíduos não tenham conhecimento e informações suficientes para cumprirem o seu papel, eles poderão ocasionar desequilíbrio ecológico, a proliferação de doenças nos animais e, em alguns casos, serem processados judicialmente.

Vale frisar que já existem inúmeras medidas que auxiliam na redução do número de atropelamentos, sendo que a mais eficaz é a construção de passagens de fauna. Alguns exemplos são: bueiros a cada dois quilômetros, viadutos de fauna, elevados, construções de cercas, passagens de fauna aéreas e passagens de fauna inferiores (PIF) (ABRA, 2012). Medidas de travessia seguras para os animais são necessárias para a conservação da biodiversidade e também para a mitigação de acidentes em rodovias, e por isso são economicamente justificadas (HUIJSER; ABRA; DUFFIELD, 2013).

\section{Referências}

ABRA, F. et al. Pay or prevent?: human safety, costs to society and legal perspectives on animalvehicle collisions in São Paulo state, Brazil. Plos One, [s.I.], v. 14, n. 4, Apr. 2019. DOl: https:// doi.org/10.1371/journal.pone.0215152. Disponível em: https://journals.plos.org/plosone/ article?id=10.1371/journal.pone.0215152. Acesso em: 15 mar. 2021. 
ABRA, F. Monitoramento e avaliação das passagens inferiores de fauna presentes na rodovia SP-225 no município de Brotas, São Paulo. 2012. Dissertação (Mestrado em Ecologia: Ecossistemas Terrestres e Aquáticos) - Universidade de São Paulo, São Paulo, 2012. DOI: https:// doi.org/10.11606/D.41.2012.tde-21012013-095242. Disponível em: https://teses.usp.br/teses/ disponiveis/41/41134/tde-21012013-095242/pt-br.php. Acesso em: 15 mar. 2021.

ACOSTA, R. 0 tráfico internacional de animais silvestres. In: BRASIL. Ministério das Relações Exteriores. O Brasil no Combate ao Tráfico de Animais Silvestres. Brasília, DF: 2004.

AMARAL, A.; MALTA, D.; LIBORIO, F. Curso de manejo imediato de animais silvestres em atividades fiscalizatórias. Salvador: Ministério Público do Estado da Bahia, 2015. Disponível em: https://www. mpba.mp.br. Acesso em: 15 mar. 2020.

ANDRADE, S. F. Manual de terapêutica veterinária. 2. ed. São Paulo: Roca, 2002. 697 p.

ARAUJO, A. C. B. et al. Diagnóstico sobre a avifauna apreendida e entregue espontaneamente na região central do Rio Grande do Sul. Revista Brasileira de Biociências, Porto Alegre, v. 8, n. 3, p. 279-284, jul./set. 2010.

BANDEIRA, C.; FLORIANO, E. P. Avaliação de impacto ambiental de rodovias, Caderno Didático, Santa Rosa, no 8, 2004. 16 p.

BARUERI. Prefeitura Municipal de Barueri. Secretaria de Recursos Naturais e Meio Ambiente. Centro de Triagem de Animais Silvestres - Cetas Barueri. Disponível em: http://portal.barueri.sp.gov.br/ secretarias/secretaria-recursos-naturais-meio-ambiente/cetas. Acesso em: 23 mar. 2020.

BASTOS, L. F. et al. Apreensão de espécimes da fauna silvestre em Goiás: situação e destinação.

Revista de Biologia Neotropical, Rio Verde, v. 5, n. 2, p. 51-63, 2008. DOI: https://doi.org/10.5216/ rbn.v5i2.9822.

BERTOZZO, D. et al. Contenção química em animais silvestres. Revista Científica Eletrônica de Medicina Veterinária, Garça, ano 6, n. 11, jul. 2008. Disponível em: http://faef.revista.inf.br/ imagens arquivos/arquivos destaque/VTjtBxuflaNUM9k 2013-5-29-12-37-40.pdf. Acesso em: 7 maio 2020.

BRANCO, A. Modelo de gestão de fauna silvestre nativa vitimada para as Secretarias de Saúde, Meio Ambiente e Segurança Urbana: Prefeitura de São Paulo. 2015. Tese (Doutorado em Saúde Ambiental) - Universidade de São Paulo, São Paulo, maio 2015. DOl: https://doi. org/10.11606/T.6.2015.tde-29052015-124750. Disponivel em: https://teses.usp.br/teses/ disponiveis/6/6134/tde-29052015-124750/pt-br.php. Acesso em: 08 maio 2020.

BRANCO, A. Políticas públicas e serviços públicos de gestão e manejo da fauna silvestre nativa resgatada: estudo de caso: Prefeitura da Cidade de São Paulo. 2008. Dissertação (Mestrado em Saúde Ambiental) - Universidade de São Paulo, São Paulo, set. 2008. DOI: https://doi. org/10.11606/D.6.2008.tde-24092008-152402. Disponível em: https://teses.usp.br/teses/ disponiveis/6/6134/tde-24092008-152402/pt-br.php. Acesso em: 8 maio 2020.

BRASIL. Instrução Normativa n²3, de 31 de dezembro de 2014. Ministério do Meio Ambiente. Diário Oficial da União: seção 1, Brasília, DF, p. 115. 2 jan. 2015. Disponível em: http://www.in.gov. br/materia/-/asset_publisher/Kujrw0TZC2Mb/content/id/32094529/do1-2015-01-02-instrucaonormativa n-23-de-31-de-dezembro-de-2014-32094512. Acesso em: 22 maio 2020.

BRASIL. Lei Complementar no 140, de 08 de dezembro de 2011. Fixa normas, nos termos dos incisos III, VI e VII do caput e do parágrafo único do art. 23 da Constituição Federal, para a cooperação entre a União, os Estados, o Distrito Federal e os Municípios nas ações administrativas decorrentes do exercício da competência comum relativas à proteção das paisagens naturais notáveis, à proteção do meio ambiente, ao combate à poluição em qualquer de suas formas e à preservação das florestas, da 
fauna e da flora; e altera a Lei n 6.938, de 31 de agosto de 1981. Diário Oficial da União, Brasília, DF, 9 dez. 2011. Disponível em: http://www.planalto.gov.br/ccivil_03/leis/lcp/lcp140.htm. Acesso em: 29 abr. 2021.

BRASIL. Lei n 5.197, de 3 de janeiro de 1967. Dispõe sobre a proteção à fauna e dá outras providências. Diário Oficial da União: seção 1, Brasília, DF, p. 177, 5 jan. 1967. Disponível em: http:// www.planalto.gov.br/ccivil_03/leis/L5197.htm. Acesso em: 21 maio 2020.

BRASIL. Lei n 9.605, de 12 de fevereiro de 1998. Dispõe sobre as sanções penais e administrativas derivadas de condutas e atividades lesivas ao meio ambiente, e dá outras providências. Diário Oficial da União: seção 1, Brasília, DF, p. 1, 13 fev. 1998. Disponível em: http://www2.mma.gov.br/port/ conama/legiabre.cfm?codlegi=320. Acesso em: 15 maio 2020.

BRASIL. Lei n 9.985, de 18 de julho de 2000. Diário Oficial da União: seção 1, Brasília, DF, p. 1, 19 jul. 2000. Disponível em: http://www.planalto.gov.br/ccivil 03/leis/I9985.htm. Acesso em: 12 maio 2021.

BRASIL. Ministério do Meio Ambiente. Instituto Brasileiro do Meio Ambiente e dos Recursos Naturais Renováveis. Centro de Triagem de Animais Silvestres, jun. 2018. Disponível em: https://www.ibama. gov.br/fauna-silvestre/cetas/o-que-sao-os-cetas. Acesso em: 10 abr. 2020.

BRASIL. Resolução n489, de 26 de outubro de 2018. Define as categorias de atividades ou empreendimentos e estabelece critérios gerais para a autorização de uso e manejo, em cativeiro, da fauna silvestre e da fauna exótica. Diário Oficial da União: seção 1, Brasília, DF, p. 69, 29 out. 2018. Disponível em: https://www.in.gov.br/materia/-/asset_publisher/Kujrw0TZC2Mb/content/ id/47542644/do1-2018-10-29-resolucao-n-489-de-26-de-outubro-de-2018-47542603. Acesso em: 1 maio 2021.

CBEE - CENTRO BRASILEIRO DE ESTUDOS EM ECOLOGIA DE ESTRADAS. Universidade Federal de Lavras. Banco de atropelamento de fauna selvagem. Disponível em: http://cbee.ufla.br/portal/ atropelometro/. Acesso em: 10 abr. 2020.

CBEE - CENTRO BRASILEIRO DE ESTUDOS EM ECOLOGIA DE ESTRADAS. Sistema Urubu: a ciência cidadã em prol da conservação da biodiversidade, 2014. Disponível em: https://www.sistemaurubu.com.br/. Acesso em: 27 abr. 2021.

CIRINO, D. W.; FREITAS, S. R. Quais são os mamíferos mais atropelados no Brasil? Santo André: Universidade Federal do ABC, nov. 2018. Disponivel em: https://www.researchgate.net/ publication/331274623. Acesso em: 23 mar. 2020.

CLARK JUNIOR, E. E. El papel potencial de la reabilitación en la conservación de vida silvestre en las Américas. In: DREWS, C. (ed.) Rescate de fauna em el Neotrópico. Heredia: Euna, 1999. p. 31-52.

CUBAS, Z. S.; ANDRADE, S. F. Manual de Terapêutica Veterinária. 2. ed. São Paulo: Roca, 2002. 569 p.

DI GIULIO, M; HOLDEREGGER, R.; TOBIAS, S. Effects of habitat and landscape fragmentation on humans and biodiversity in densely populated landscapes. Journal of Enviromental Management, [s.l.], v. 90, n. 10, p. 2959-2968, jul. 2009. DOI: https://doi.org/10.1016/j.jenvman.2009.05.002.

GONÇALVES, A. Biopirataria: novos rumos e velhos problemas. Direitos Culturais, Santo Ângelo, v. 4, n. 6, 2009.

GONÇALVES, A. Estudo do impacto causado a fauna silvestre por rodovias brasileiras que fragmentam áreas florestais. 2018. Trabalho de Conclusão de Curso (Especialização em Gestão Ambiental em Municípios) - Universidade Tecnológica Federal do Paraná, Medianeira, 2018. Disponível em: http://repositorio.roca.utfpr.edu.br/jspui/handle/1/15578. Acesso em: 15 mar. 2020. 
HERNANDEZ, E.; CARVALHO, M. O tráfico de animais silvestres no Paraná. Acta Scientiarum Human and Social Sciences, Maringá, v. 28, n. 2, p. 257-266, 2006.

HUIJSER, M.; ABRA, F.; DUFFIELD, J. Mamma road mortality and cost-benefit analyses of mitigation measures aimed at reducing collisions with cabybara (Hydrochaeris hydrochaeris) in São Paulo state, Brazil. Oecologia Australis, [s.I.], v. 7, n. 1, 2013. Disponível em: https://revistas.ufrj.br/index.php/ oa/article/view/8261. Acesso em: 15 mar. 2021.

ICMBIO - INSTITUTO CHICO MENDES DE CONSERVAÇÃO DA BIODIVERSIDADE. Livro vermelho da fauna brasileira ameaçada de extinção. Brasília, DF, 2018. Disponível em: https://www.icmbio.gov.br/ portal/images/stories/comunicacao/publicacoes/publicacoes-diversas/livro_vermelho_2018_vol1. pdf. Acesso em: 29 abr. 2020.

ICMBIO - INSTITUTO CHICO MENDES DE CONSERVAÇÃO DA BIODIVERSIDADE. Planos de Ação Nacional para a Conservação das Espécies Ameaçadas de Extinção ou do Patrimônio Espeleológico (PAN). Brasília, DF, 2021. Disponível em: https://www.icmbio.gov.br/portal/faunabrasileira/planos-de-acaonacional. Acesso em: 12 maio 2021.

KILPATRICK, H. J.; SPOHR, S. M. Tiletamina-xylazine versus ketamine-xylazine: a field evaluation for immobilizing white-tailed deer. Wildlife Society Bulletin, [s.I.], v. 27, n. 3, p. 566- 570, 1999.

KRISHNASAMY, K.; STONER, S. Trading Faces: a rapid assessment on the use of Facebook to trade wildlife in peninsular Malaysia, Traffic Report, [s.l.], 2016. Disponível em: http://www.trafficj.org/ publication/16 Trading_Faces.pdf. Acesso em: 21 maio 2020.

LACAVA, U. (coord.) Tráfico de animais silvestres no Brasil: um diagnóstico preliminar. Brasília, DF: WWF - Brasil, 2000. 54p.

LIMA, S. F.; OBARA, A. T. Levantamento de animais silvestres atropelados na BR-277 às margens do Parque Nacional do Iguaçu: subsídios ao programa multidisciplinar de proteção à fauna. In: SEMANA DE ARTES DA UNIVERSIDADE DE MARINGÁ, 7., 2004, Maringá, Anais [...]. Maringá, 2004.

MASSONE, F. Anestesiologia veterinária: farmacologia e técnicas. 4. ed. São João da Boa Vista: Guanabara Koogan, 2003. 326 p.

PANAZZOLO, A. P. et al. Gestão ambiental na construção de rodovias - o caso da BR-448 - Rodovia do Parque. In: CONGRESSO INTERNACIONAL DE TECNOLOGIAS PARA O MEIO AMBIENTE, 3., Bento Gonçalves. Anais [...]. Bento Gonçalves, abr. 2012.

PRIMACK, R. B.; RODRIGUES, E. Biologia da conservação. Londrina: Planta, 2001. 328 p.

RENCTAS - REDE NACIONAL DE COMBATE AO TRÁFICO DE ANIMAIS SILVESTRES. 10 Relatório Nacional Sobre o Tráfico de Fauna Silvestre. Brasília, DF, 2001.

SÃO PAULO (Estado). Agência de Transporte do Estado de São Paulo. Artesp e concessionárias de rodovias atuam na preservação do meio ambiente, jun. 2019. Disponível em: http://www.artesp.sp.gov. br/Style\%20Library/extranet/noticias/noticiadetalhes.aspx?id=247. Acesso em: 25 mar. 2020.

SÃO PAULO (Estado). Departamento de Águas e Energia Elétrica. Centro de Recuperação de Animais Silvestres - CRAS. Disponível em: http://www.daee.sp.gov.br/index.php?option=com content\&id=517: cras-centro-de recuperacao-de-animais-silvestres\&ltemid=53. Acesso em: 25 mar. 2020.

SÃO PAULO (Estado). Decreto no 64.132, de 11 de março de 2019. Dispõe sobre a organização da Secretaria de Infraestrutura e Meio Ambiente e dá providências correlatas. Diário Oficial do Estado de São Paulo: São Paulo, SP, v. 129, n. 47, 12 mar. 2019. Disponível em: https://www.al.sp.gov.br/ repositorio/legislacao/decreto/2019/decreto-64132-11.03.2019.html. Acesso em: 11 maio 2021.

SHAFER, C. L. Nature reserves: island theory and conservation practice, Washington DC: Smithsonian Institution Press, 1990.189 p. 
SPINOSA, H. S.; GORNIAK, S. L.; BERNARDI, M. M. Farmacologia aplicada a Medicina Veterinária. 2. ed. Rio de Janeiro: Guanabara Koogan, 1999. p. 165-178.

UNIVERSIDADE FEDERAL DE MINAS GERAIS. Cadernos Técnicos de Veterinária e Zootecnia:

ECOAS, Belo Horizonte, n. 72, fev. 2014. Suplemento. Disponível em: https://issuu.com/ escoladeveterinariaufmg/docs/caderno_tecnico_72_epidemiologia_e_. Acesso em: 25 abr. 2020.

USP - UNIVERSIDADE DE SÃO PAULO. Prefeitura do Campus da Capital. Resgate de animais silvestres acidentados/feridos e denúncia de crimes contra animais silvestres. Disponível em: https://puspc. usp.br/policia-militar-ambiental/. Acesso em: 26 mar. 2020.

VIDOLIN, G. P. et al. Programa estadual de manejo da fauna silvestre apreendida. Cadernos da Biodiversidade, [s.I.], v. 4, n. 2, dez. 2004.

$\mathrm{YU}, \mathrm{X}$; JIA, W. Moving targets: tracking online sales of illegal wildlife products in China,

Traffic Brieffing, [s.I.], Feb. 2015. Disponível em: http://static1.1.sqspcdn.com/

static/f/157301/26245505/1432122394320/China-monitoringreport.pdf. Acesso em: 21 maio 2020. 